University of Rhode Island

DigitalCommons@URI

Civil \& Environmental Engineering Faculty

Publications

Civil \& Environmental Engineering

2017

\title{
Adhesion Evaluation of Duplex Paint System for Sustainable Infrastructure
}

Sze C. Yang

University of Rhode Island, syang@uri.edu

Kang-Won Wayne Lee

University of Rhode Island, leekw@uri.edu

Chen Lu

University of Rhode Island

Maureen Mirville

University of Rhode Island

Follpw this and additional works at: https://digitalcommons.uri.edu/cve_facpubs

The University of Rhode Island Faculty have made this article openly available.

Please let us know how Open Access to this research benefits you.

This is a pre-publication author manuscript of the final, published article.

Terms of Use

This article is made available under the terms and conditions applicable towards Open Access

Policy Articles, as set forth in our Terms of Use.

Citation/Publisher Attribution

Yang, S., Lee, K. W., Lu, C., Mirville, M., \& Parham, A. (2017). Adhesion Evaluation of Duplex Paint System for Sustainable Infrastructure. Journal of Materials in Civil Engineering, 29(9), 04017134. doi:

10.1061/(ASCE)MT.1943-5533.0001909

Available at: http://dx.doi.org/10.1061/(ASCE)MT.1943-5533.0001909

This Article is brought to you for free and open access by the Civil \& Environmental Engineering at DigitalCommons@URI. It has been accepted for inclusion in Civil \& Environmental Engineering Faculty Publications by an authorized administrator of DigitalCommons@URI. For more information, please contact digitalcommons@etal.uri.edu. 
4 Abstract. Organic paints are applied to galvanized or metalized steel surfaces in a duplex 5 system, which is potentially more sustainable than the zinc-rich primer/steel system. A series

6 of experimental tests were performed to measure and investigate adhesion strengths on three

7 different types of roughened zinc surfaces. The contact angles were also measured for freshly

8 formulated liquid paints on the roughened zinc surfaces to test if there is a correlation between

9 the paint wetting property and the adhesive strengths. By comparing duplex system and zinc-

10 rich primer/steel qualified North East Protective Coating (NEPCOAT) panels, it was found the

11 paint adhesion of duplex system is as strong as the zinc primer/steel panels based test results.

12 It was also found that adhesive strengths depend on the match between the paint and type of 13 roughened zinc surfaces. The measurement of liquid paint wetting properties indicates small 14 contact angles correlate with stronger pull-off adhesive strength. The authors of this study 15 suggest that contact angle/strength correlation could be useful as a tool for optimizing the 16 match between paints and the profiled zinc surface.

18 KEY WORDS: Paint adhesion, Galvanized steel, Metalized steel, Duplex system, Paint 19 adhesion, Paint wetting, Bridge painting.

20

${ }^{1}$ Sze C. Yang, Ph.D., Professor of Chemistry, the University of Rhode Island, Kingston, 22 RI 02881, USA (401) 874-2377, syang@uri.edu 
${ }^{2}$ K. Wayne Lee, Ph.D., P.E., F. ASCE, Professor and Director of RI Transportation

24 Research Center (TRC), Department of Civil and Environment Engineering, the University of 25 Rhode Island, Kingston, RI 02881 (401)874-2695, leekw@ uri.edu, Corresponding author

${ }^{3}$ Chen Lu, Graduate Student, Department of Chemistry, the University of Rhode

27 Island, (401) 241-9773, binbinluchen@gmail.com

${ }^{4}$ Maureen Mirville, Research Assistant, Department of Chemistry, the University of

Rhode Island, (781) 724-7098, Maureen.mirville@gmail.com

${ }^{5}$ Anthony Parham, Graduate Student, Department of Chemistry, the University of Rhode

31 Island, (508) 963-3076, antparham@ @otmail.com

Introduction

34 For many highway transportation steel structures, a metallic zinc coating is applied to the 35 structural steel to act as a sacrificial layer for corrosion protection. Zinc is applied to steel in 36 three ways - by zinc-rich primer paint, by metalizing (where hot zinc is sprayed onto the steel

37 surface), or by galvanizing (where the steel part is immersed in a molten zinc bath and a zinc 38 layer on the steel).

Paints are often applied to the zinc-coated steel surfaces for additional corrosion

40 protection and for an aesthetic color finish. The system of dual protection of steel structure with 41 zinc and paint is called the "duplex system". Although the corrosion protection of steel is

42 regarded to be equal or better than that of the zinc-primer paints on bare steel, the frequent sights 43 of peeled off paints on duplex systems lead to a general impression that it is harder to achieve a 44 good paint adhesion on metallic zinc-coated steel surface than the traditional zinc primer coated 45 bare steel surface. In this project the authors compared the pull-off strengths of painted panels of 
46 both types with the intent to show that the duplex system can perform as well as the zinc-rich

47 paints on steel if the zinc surface is roughened and the pairing between paint and substrate is 48 properly chosen.

The coating industry had long recognized that paint adheres poorly on a smooth metallic zinc surface formed by hot-dip galvanizing. A freshly galvanized zinc surface is shinny and

51 smooth. Paint adhesion on the shinny surface is poor. The zinc surface needs to be profiled (or

52 roughened) to provide a "bite" between the paint and the zinc/steel surface. Roughening by blast

53 profiling and mechanical grinding are two methods used in commercial galvanizers and painters.

54 Since the metallic zinc layer is relatively thin, the roughening process for galvanized steel is 55 somewhat delicate.

Thermal spray of molten zinc droplets onto steel surface (a process known as zinc

57 metalizing) is increasingly used as an alternative to hot-dip galvanizing. The sprayed-on molten

58 zinc droplets result in naturally rough zinc surface so there is no need for the additional step of

59 roughening. The metalized test panels (labeled as M0 test panels) were tested along with the

60 galvanized/blast profiled test panels (labeled as Gb0 test panels) and the

61 galvanized/mechanically-roughened panels (labeled as M0 test panels) in this study for

62 comparisons. The NEPCOAT qualified zinc-rich primers (labeled as $\mathrm{Z}$ test panels) on

63 bare/blasted steel were tested as a benchmark to compare with the three types of roughened

64 metallic zinc surfaces. Because of the space limitation the results are not discussed here in

65 details. The main conclusion from the comparison with the three types of roughened zinc

66 surfaces with the zinc-rich primer benchmark is that the pull-off strengths are strong and

67 comparable as long as the liquid paint droplet contact angles are smaller than a certain threshold.

68 The focuses of this report are (1) the comparison of the pull-off strengths on three different 
roughened zinc surfaces, and (2) the verification that low liquid paint contact angle correlates

70 with strong pull-off strength of the cured paints. The adhesion tests were performed on coatings

71 cured less than 1 month old. The long-term salt-spray and electrochemical impedance studies on

72 these test panels have not been done for this paper. In this paper only the adhesion tests before

73 weathering are reported.

In the present study three different types of zinc-on-steel substrates were prepared for

75 painting:

76 1. Galvanized and blast roughened test panels (abbreviated as G0b substrates),

77 2. Galvanized and mechanically roughened test panels (abbreviated as G0m substrates), and

78 3. Metalized (thermal sprayed zinc on steel) panels (abbreviated as M0).

The wetting properties of different profiled zinc surfaces have not been studied

80 previously, even though the conventional wisdom shared among painters is that if the paint beads

81 up (large droplet contact angles) the paint will not adhere well. One of the objectives of this

82 study is to experimentally measure the wetting properties of a variety of paints on three

83 differently roughened zinc-on-steel surfaces and to correlate with the adhesive strength of the

84 coating after curing. In the field of surface science the liquid droplet contact angle on a solid

85 surface is often used as an indicator for the extent of wetting. In 1964 Zisman (Zisman 1964)

86 discussed the reasons why a small contact angle indicates efficient wetting of the liquid adhesive

87 on solid surfaces, and why wetting of paint is a prerequisite for strong adhesive bonding.

A roughened zinc surface is potentially beneficial for stronger paint adhesion for the

89 following reasons: (1) Roughness increases metal surface areas for paint molecules to physically

90 adsorb or chemically bond to the metal atoms. (2) The surface roughening processes create

91 channels, the capillaries, and the pores. Paint penetration into the channels, capillaries and pores 
creates mechanical interlocking that interrupts crack propagation at the interface. (Zisman 1964, Petrie 2012).

These benefits afforded by zinc surface roughening are realized only if the liquid paint wets the channels, the capillaries and the pores. Since a small liquid paint contact angle indicates that the liquid-solid attractive force is stronger than the solid-air attractive by the paint resin could create mechanical interlocking. Although the roughened Since molecular contact (within $5 \AA$, or $5 \times 10^{-8} \mathrm{~cm}$ ) is required for adsorption and chemical bonding between the cured paint It also provides anchor spots for the dried paint to mechanically lock onto the surface. These advantages would not materialize if during the painting process the liquid paint sprayed on the surface could not wet and penetrate the roughened surface. If the liquid paint does not wet the nukes and crannies of the roughened zinc surface, it will trap air between the paint and zinc interface. With the undesirable air-gap between the coating and the metal surface the physical adsorption and chemical bonding would not take place, and thus the potential binding sites are underutilized. Furthermore, the air gaps, even microscopic in size, become the seeds and links to enhance the interfacial crack propagation that is a likely reason for the frequent sight of the peeling off of paints on galvanized or metalized steel structures. (a mixture of metallic zinc, zinc oxide, zinc hydroxide, and surface contaminants) is the driving force for wetting and spreading of a liquid droplet on the surface. A strong attractive force at the liquid-solid interface flattens the droplet to decrease the contact angle $\theta$. The balance of the forces can be derived with the thermodynamic principle that minimizes the Gibb's Free Energy of the system. The relevant material properties are the surface tensions for three different 
115

116

117

118

119

120

121

122

123

124

125

126

127

128

129

130

131

132

133

134

135

136

137

interfaces, $\gamma_{L V}$ for the liquid/vapor interface, $\gamma_{S V}$ for the solid/vapor interface, and $\gamma_{S L}$ for the

solid/liquid interface. The spreading coefficient, $S{ }_{S V}\left({ }_{S L}+{ }_{L V}\right)$, is an index for flattening and spreading of the liquid droplet (de Gennes 1985). If $S<0$, the liquid droplet partially wets the solid surface with a finite contact angle $\theta$ to form a liquid cap. The contact angle decreases when the spreading coefficient approaches zero. A liquid droplet completely spreads to wet the solid surface when the contact angle is zero and $\mathrm{S}=0$.

A droplet (e.g., Mercury) on a flat surface (e.g., glass) beads up if S is greater than zero. In our test panels the surface are rough, not flat. In some special cases of this study the paint droplets were found to bead up with high contact angles. The reason for the beading of the paint droplet is different from that of the Mercury-on-glass system. It is due to the super-hydrophobic effect on certain roughened surface (Chow 1998). For $S \quad 0$, the contact angle $\theta$ are related to $\mathrm{S}$ according to the Young-Dupre equation (Bonn 2009).

$$
S_{L V}={ }_{S V} \quad{ }_{L V} \quad{ }_{S L} \underset{S V \quad \frac{\text { Young's equation }}{{ }_{S L}={ }_{L V} \operatorname{Cos}}}{\longrightarrow}{ }_{L V}(\cos \quad 1)
$$

Equation (1) shows that wetting of the surface is favored when the value of the surface tension $\gamma_{\mathrm{LV}}$ for the liquid-vapor interface is small, and the contact angle $\theta$ is small.

In the present study the authors address following questions: Would one method of profiling (surface roughening) more advantageous than the other method? How would the adhesive strength of the paints on profiled galvanized steel compare with the metalized zinc surface?

For the organic paints, 4 paint systems from the North East Protective Coating (NEPCOAT, http://www.nepcoat.org/qualprod.htm) qualified list B were used. In addition to the NEPCOAT paints, a commercial epoxy liquid sealer for zinc-metalized steel. All paints were formulated at the same commercial paint coating company, and test panels were spray painted 
with the formulated liquid paints immediately after the formulation (including the "sweat" times if applicable). The zinc coatings were done on the same day of the painting work.

It is generally believed that good liquid paint wetting on a substrate surface is important for strong adhesive strength of the cured organic epoxy coating. There is no doubt this conventional wisdom holds true for the same formulation of paint on the same type of substrate surface. For a single pair of paint/surface poor wetting is a result of improperly cleaned surface. In this study 5 different paint formulations and 3 different profiled zinc surfaces were used. This allows the authors to investigate the question of whether there is a correlation between wetting and the adhesive strength across the different choices of paint/surface pairs. If such correlation exists, could one use the data to optimize the adhesive strength by matching a specific paint with one of the profiled surfaces (metalized, galvanized and mechanically roughened, or galvanized and blast profiled)? Fortunately, the experimental results suggest this type of paint/surface matching might be possible and beneficial. In this study the contact angle of freshly formulated liquid paint droplet on the profiled zinc surface were used as an index for paint/surface wetting property (Ziesman 1964). The pull-off strength of the cured paint were tested according to the ASTM D4541 standard procedure.

\section{Experimental Works}

\section{Test Panel Preparation and the Work Plan}

Steel Base Panels: The steel test panels were purchased from KTA-Tator Corp (Pittsburgh, PA) The dimension of the cold-rolled steel was 4" x 6" x 1/4" in, and two types of base panels were used for this study. Type A panel is a steel plate with a U-shaped "channel" welded perpendicularly at one end of the panel to emulate a structure with welded joints. Each panel has 
161 a $1 / 4$ in. mounting hole located near the top end of the panel. Panels were identified via three162 digit number inscribes (or stamped) in the panel, top front face. Type B base panel was a flat 163 rectangle plate. The diagrams showing the design for the steel base panels are shown in Fig. 1.

164 Both types of steel panels underwent the following processes for coating with zinc 165 metal and for profiling the surface: (1) they were coated with metallic zinc by either 166 galvanizing or metalizing, and (2) the galvanized plates were roughened by either blasting or 167 by mechanical grinding to produce a profiled zinc surface.

Galvanizing were performed by Duncan Galvanizing, Everett, MA and V\&S 169 Galvanizing, Taunton, MA. Galvanizing was performed according to ASTM A123 dry kettle 170 process, no water quenching, no chromate conversion. Duncan supplied galvanized test 171 panels roughened by mechanical profiling. V\&S supplied galvanized test panels roughened 172 by sweep blasting according to the respective ASTM standards.

173 The thickness of zinc coating by galvanizing ranges from 3.0 to 4.0 mil with RMS 174 thickness at 0.4 mil. The roughness profile for galvanized zinc surface is between 1 to 2 mils. The thickness of zinc coating by thermal spray is 6 to 10 mils. The surface of thermal 176 sprayed zinc is porous with internal channels of complex structures.

After the surface profiling is completed, the Type A and Type B panels were used for 179 different purposes. The Type A panels were painted with 4 different commercial paint systems 180 from the NAPCOAT qualified list B (North 2016) to produce panels for adhesion strength tests. 181 The Type B panels were used for the measurement of the wetting property of liquid paint on the 182 profiled zinc surface. All test panels reported here are freshly galvanized, roughened and spray 183 painted on the same day. The commercial paint formulations were prepared and spray-painted 
by Boyed Coatings Research, Hudson, MA. The contact angle measurements were performed on 185 Type B panels using the same freshly formulated paint applied to Type A panels. The contact angle measurements were measured at the same time when the spray paintings were performed.

The pull-off strength tests of the cured paints were performed according to the procedure of ASTM D4541 using a PosiTest AT-M tester. The X-cut adhesive tape tests were performed according to the procedure of ASTM D3359.

\section{Zinc Coating on Steel Test Panels}

Galvanized test panels were prepared per ASTM A123 by Duncan Group, Everett, MA, and by V\&S Galvanizing, Taunton, MA. Metalizing was performed per SSPC-CS23.00/AWS C2.23M/NACE No. 12 Specification for the "Application of Thermal Spray Coatings (Metalizing) of Aluminum, Zinc and Their Alloys and Composites for the Corrosion Protection of Steel". The metalizing was performed by Falmer Thermal Spray, Salem, MA. In addition to test panels a control group of test panels named Group $\mathrm{Z}$ were tested for comparison. The Group $\mathrm{Z}$ panels were not galvanized or metalized but were painted with zinc rich organic primers as the zinc containing layer. The organic zinc primers were selected from the list of NEPCOAT approved list of primers for bare steel. The organic zinc primers were applied on the control steel panels according to the technical specification from the zinc primer paint manufacturers.

\section{Preparation of Surface Profiled Zinc Metal Substrates}

The photographic images and test data of the Type A test panels after the pull-off and x-cut adhesion tests were documented in a supplemental report NETCR93 available from New England Transportation Consortium (NETC) (Yang et al. 2013). 
Test Panel Group G0m: The G0m zinc coated metal substrates were galvanized steel profiled

207 by mechanical grinding of the zinc surface to produce surface roughness.

The galvanizing and mechanical profiling of zinc surface was performed at a plant D.

209 The galvanizing and mechanical profiling of the surface were performed on the same day. This 210 group of test panels were labeled as group G0m, where "G" signifies "Galvanizing", "0"

211 signifies zero delay, and "m" signifies "mechanical profiling".

212 Test Panel Group G0b: G0b is a group of galvanized steel profiled by sweep blasting to 213 produce rough surfaces. The galvanizing and blast profiling process were performed by another 214 plant $\mathrm{V}$, using aluminum oxide grit to produce a profile of 1-2 mils.

216 This group of test panel is designated as group "G0b”. In this group name, "G" signifies

217 galvanizing as the process of coating zinc, "0" signifies zero delay (within the same day, less

218 than 3 hours) between galvanizing and profiling of the surface, and " $b$ " signifies the use of

219 blasting as a means for surface roughening.

220 Test Panel Group M0: For the group of M0, zinc coated steel substrates were produced by

221 thermal spray of molten zinc particles on steel. Since the surface of the zinc-metalized steel is

222 rough and porous no further surface profiling was required. The zinc metalized steel test panels

223 were processed by a metallizer F, using $99.99 \%$ zinc wire thermal sprayed over steel panels

224 blasted with aluminum oxide grit to produce a 2 mil profile.

The code name "M0" was designated for this group of test panels, where "M" signifies

226 the "metalizing", and " 0 " signifies zero delay in surface profiling. There is zero delay for

227 profiling because the rough surface is an inherent property of the metalized surface.

\section{Test Panel Group Z:}


The authors were aware the importance of the inorganic zinc primers as specified in

230 NEPCOAT qualified list A. In this specific research project the authors used organic zinc 231 primer in accordance with the suggestion of the technical committee of the sponsoring agency, 232 NETC.

233 A set of panels containing organic zinc rich primer was prepared as a reference for 234 comparing with the galvanized and the metalized steel test panels. The steel panels were 235 white blasted before application of the zinc-rich primer. The code name "Z" signifying "Zinc 236 rich organic primer" were given for this group of test panels.

237

238

239

240

241

242

243

244

245

246

247

248

249

250

251

\section{Fabrication of the Galvanized and Metalized Test Panels}

Our research team delivered the steel panels to the zinc coating facilities on the day prior to the zinc coating event. Plants D and V performed the galvanization in the morning following the date of steel panel delivery. The measured thickness of zinc coating was in the range of 3.0 to 3.7 mil.

For test panel groups G0m, and G0b, the galvanizers performed the mechanical or blast profiling on the same morning of galvanizing. Researchers from the University of Rhode Island (URI) picked up the zinc-coated panels before noon on the day of the coating event. URI researchers then transported the zinc coated and surface profiled metal plates to paint shop B at noon of the same day. Workers at paint shop B started mixing two-part epoxy paints and begin spray painting on the Type A zinc coated metal substrates in the early afternoon of the same day. Portions of the freshly mixed liquid paints were brought to a room in paint shop B where the URI researchers measured the wetting and spreading properties of small paint droplets (with volume about $1 \mu \mathrm{L}$ ) on zinc coated and profiled Type B test panels prepared from the same batch of galvanizing or metalizing process. The shape parameters of the droplets were measured as a 
252 function of time using a goniometer. The parameters recorded include the contact angle, the

253 height and the diameter of the liquid/solid contact area.

For test panel group M0, a metalizer F coated zinc metal on Type A steel substrates by

255 thermal spray during the morning. The zinc coating thickness was $6-10$ mils according to

256 SSPC-PA2 specification. The URI researchers picked up the metalized panels at noon and

257 brought them to paint shop B at noon of the same day.

\section{Application of Paints on Metal Substrates}

259 Paint Systems Coated on the Test Panels: Five systems of commercial paints from the NAPCOAT list B (North 2016) were applied to the Type A test panels. The components of these

2615 paint systems are described in Table 1. The code names C, I, S1, S2 and S3 were adopted in 262 this paper as the abbreviations for the paint systems.

263 Paint Systems Coated on the Control Panels: The control panels have the same systems of 264 the Intermediate and the Finish (Top) paints as those used for the test panels but used an 265 organic Zinc-Rich Primer from the NEPCOAT approved list of primers for bare steel. The 266 zinc rich primers used for control Panels are listed in Table 2. The coated control panels were 267 labeled with a code starting with $\mathrm{Z}$ signifying the zinc-rich primer on steel surface. The 268 control panels as Z-C, Z-I, Z-S1, and Z-S2 were used to signify the paint system used for 269 fabricating the zinc-rich primer test panels

270 The pull-off test result: illustrative examples: Pull-off strength tests were performed according 271 to the procedure of ASTM D4541 using PosiTest AT-M. Figure 2 shows the pull-off tester and 272 the test panels.

273 Figure 3 shows a photograph of the pulled-off dolly (at left) and a test spot (at right) from 274 Test 1 of Panel \#641. The Pull-off Strength was 2,241 psi measured with the PosiTest Pull-off 
tester. The dolly was placed on the test panel near the test spot. Because the dolly surface is about $3 / 4$ in. closer to the lens of the camera, it appears to be larger than the test spot.

Figure 3 shows the coexistence of two kinds of break interfaces. The green colored area, with about $80 \%$ of the dolly surface coverage, shows coherent break within the Top paint. The grey area on the left of the dolly surface and at the peripheral area of the island at the right of the dolly surface is judged as the cohesive break within the intermediate paint. The middle region on the island at the right shows spots of shiny reflection. This shiny and flat region is the contacting interface between the intermediate paint and the galvanized zinc surface. This shinny region (estimated to be about $10 \%$ of the surface of the dolly) is recorded as the adhesive break between the intermediate paint and the Galvanized Zinc surface.

Figure 4 shows another example of the image of a Pull-off Test dolly and test spot for a zinc metalized steel substrate. This picture shows that the break occurred at the epoxy/zinc interface. The pull off strength was much lower.

An example of the pull-off strength result for a given substrate (e.g. G0m) coated with one of the paint systems (e.g., I) is shown in Figure 5. Typical standard deviation is 250 to 300 psi for the pull-off strength measurements on a specific substrate-paint pair. For example the average strengths ( \pm std dev) for G0m-I and M0-I are $2525( \pm 260)$ psi and $1094( \pm 300)$ psi. The difference in strengths between different types of zinc surface is significantly larger than the standard deviation of the strength measurement.

Measurement of Contact Angle of Liquid Paint on Profiled Surfaces of Zinc Galvanized and Metalized Steel

A goniometer (Ramé-Hart Model 200) was used to measure the wetting properties. During the test, a small droplet (about $1 \mu \mathrm{L}$ ) of freshly formulated paint were placed on the surface of a profiled Type B test panel. A camera in the instrument was used to record the image of the 
droplet and the interface as a function of time. A software program "DROP" was used to analyze the shape of the contacting interfaces and to compute the best-fit contact angle.

The information about the wetting property of a liquid paint on a zinc-coated surface was obtained by measuring the interfacial contact parameters $(\theta=$ contact angle, $\mathrm{h}=$ height of liquid cap, $d=$ diameter of the liquid cap) of the droplets as a function of time. For some liquid/surface pairs a 10 seconds measurement was sufficient. For some other liquid/surface pairs, the useful data is contained in the parameters as a function of time for 20 minutes duration.

\section{Contact Angle Measurement Results}

A typical example of the contact angle measurement was first examined. This initial discussion serves the purpose of familiarizing the reader with the measured data and their implications. Figure 6 shows a time sequence of the image of a droplet on a profiled zinc surface. In this example, a droplet of the fresh liquid paint $\mathrm{C}$ was placed on a G0b surface (Galvanized, same day profiling/coating, blast profiled) at $\mathrm{t}=0 \mathrm{sec}$. The pictures show the image of the droplet at 2 , 6, 12, 20 and 68 seconds, respectively. All contact angles were measured as a function of time $\mathrm{t}$ after the initial liquid drop fell on the zinc surface. The $\theta$ vs. $t$ curves are available from NETC achieve. By examining all time evolutions of the droplet images the contact angles at $\mathrm{t}=6$ second on the $\theta$ vs. $t$ curves were used for comparison among different paint/substrate systems. At this point of time the contact angles have better reproducibility and the change of angles after $\mathrm{t}=6 \mathrm{sec}$ were found to be small enough to be neglected.

The figure shows that the contact angle is less than $45^{\circ}$ at $\mathrm{t}=6 \mathrm{sec}$ which means significant attractive force between the liquid paint and the surface. The contact angle at $\mathrm{t}=6$ seconds was used as a measure of the interfacial interaction. The reason for the 6-sceond delay is that for 
some more viscous paints, the $\mathrm{t}=0$ seconds droplet had not yet reached mechanical equilibrium immediately after the initial impact at the surface.

The contact angle and the droplet height $\mathrm{h}$ continued to decrease over time. The diameter of the cap expanded. This time sequence revealed another aspect of the wetting property, i.e., the spreading of the paint liquid on the surface.

By measuring the height (h), the width (d) and the contact angle simultaneously the total volume of the liquid droplet were calculated as a function of $\mathrm{t}$ for the spreading of the liquid paint. For the droplet shown in Figure 6 the volume of the droplet is nearly the same at $t=68 \mathrm{sec}$ as that at $\mathrm{t}=0 \mathrm{sec}$. This means that although the liquid paint was spreading, the paint was not absorbed into the surface voids. This implies that the profiled surface does not have microscopic channels that siphon away the paint by capillary action. Or, if there were microscopic cavities under the surface, the paint was not penetrating into the cavities as time $t$ lapsed

For droplets with slower rate of change, the photographed images as a function of time were analyzed using an image analysis program. For fast changing droplets on the surface the "auto run" mode of the goniometer were employed to capture the changes in the droplet width and height parameters without saving the photographed images.

\section{Discussions}

Experimentally Measured Correlation between Pull-off Strength and the Liquid Paint Contact Angle Table 3 shows the average pull-off strength and the liquid paint contact angle (at $\mathrm{t}=6 \mathrm{sec}$ ) for different subgroups of coatings. The subgroups are arranged according to the order of the average pull-off strength. It can be seen that for most of the test panels, the coating systems of 
"Strong" pull-off strength defined in Table 3 show contact angles in the range of 30 to 45 degrees (with an exception for G0b-S2 that has angle of 54 degree). The coating systems with "Medium" strength show contact angles scattered (35, 106 and 82 degree). The coating systems with "Weak" strength show contact angles in the 60 to 100 degrees. Table 3 shows the average contact angles for the NEPCOAT epoxy paints (C, I, S1 and S2) on the metalized zinc surface (M0) are large $(60-100$ degree $)$. The liquid droplets on the surface beaded up with images similar to that of water droplets on lotus leaves. Such phenomenon is not observed for organic liquids on smooth surfaces. It is only possible when the surface was microscopically porous for specific liquid/surface interactions (Wenzel 1936; Cassie and Baxter 1944). When the contact angles exhibit "lotus effect" (Spori et al. 2008) the paint wetting is poor and the corresponding pull-off strength is not high (in the 1000 psi range). Table 3 also shows a contrasting example in the surface-paint pair of M0-S3. In this case the same porous surface M0 absorbs a liquid droplet of paint S3 (a sealer) within 2 seconds and the contact angle is 0 at our preset measuring time at 5 seconds. In this case the surface-paint match leads to low contact angle ( 0 degree) and strong pull-off strength $(2,023 \mathrm{psi})$ due to the same interaction but at a different regime (Wana 2011).

The general trend is that the lower contact angles correlate with stronger pull-off strength. This means that despite the high possibility of interfering factors that reduce the correlation, our experimental data do show a certain degree of correlation.

Figure 7 shows the scatter plot of Pull-off Strength as a function of the contact angles for all the data pairs of Table 3. A sloped straight line was inserted in Figure 7 as a visual guide indicating that the smaller the contact angle, the higher the pull-off strength,. The trend line with negative slope is not intended to suggest a linear fit of the data. A linear fit would 
369 give a relatively poor R-squared value of 0.49 (with the corresponding Parson's correlation at $370-0.7)$. It is not surprising that the data points are scattered because of the complexity of the 371 system and the measurements. The roughened surfaces are not microscopically uniform in 372 roughness. Although the painting and contact angle measurements were performed near the 373 time of galvanizing/metalizing (within 4 hours) the fresh zinc coatings on steel will have 374 started oxidation reactions in the air. Further more, different paint formulations have different 375 solvent contents and resin contents thus influencing the flow viscosity. What the authors 376 found was that despite all other influences the contact angle still comes through as an indicator 377 for the pull-off strength. A small contact angle of a liquid paint on a particular surface 378 correlates with high pull-off strength. The contact angle is the most accessible measurement 379 to test the paint/surface attraction but is not necessarily linearly correlated with the pull-off 380 strength. The work of adhesion between the paint and the surface is likely to be more linearly 381 proportional to the pull-off strength and it is dependent on the contact angle. But the work of 382 adhesion is not directly measurable and need other details of the surface and the paint before 383 one can calculate the values.

The preceding paragraph gives reasons for contemplating a non-linear dependence of 385 the strength vs. $\theta$ plot. A grossly simplified non-linear correlation is a step-function. The 386 same data used in Fig 7 were displayed in Fig. 8 except that a step function instead of a 387 sloping linear line. The step-function line is suggestive for a threshold of contact angle. 388 Below certain threshold contact angle (in this case $\sim 50$ degrees) the pull-off strength is high, 389 and above that threshold angle the pull-off strength is lower. The step function line is drawn 390 to suggest, but not to prove the existence of two clusters of data. However, anecdotal 391 evidences in the details of the pull-off experiment provide some support to this idea. During 
392 the pull-off strength measurements not only recorded the strengths (psi) but also photographed 393 the test spots (along with the dollies for performing the pull test). Fig 3 shows that the pair of 394 surface-paint (G2b-I) as an example of low liquid contact-angle $\left(35^{\circ}\right)$ and high pull-off 395 strength (2258 psi). The break photographed after pull test for G2b-I (Fig. 3) indicates 396 cohesive break occuring mainly within the cured paint (at the top/primer paint interface, not at 397 the primer/zinc interface). In contrast, Fig 4 shows evidence of the presence of air gap due to 398 poor liquid paint wetting. The photograph of the break surfaces for the same paint (I) on a 399 different type of surface M0 shows adhesive break at the primer/zinc interface. The measured 400 liquid contact angle was high $\left(75^{\circ}\right)$, indicating the lack of wetting and the pull-off strength 401 was low (1,262 psi). The photograph in Fig 4 shows no paint left in the pores and the 402 channels of the metalized rough surface after pull-off. It is likely that the pores and channels 403 were not wetted by the liquid paint when the liquid formulation was sprayed on. This is 404 consistent with the high contact angle $\left(75^{\circ}\right)$ and the lack of wetting. The lack of liquid paint 405 wetting leads to the presence of air gap, and in turn the cause for poor pull-off strength (1260 406 psi). The photographs of the break surfaces were recorded in our NETC report. Upon 407 examination of the photographs it was found that almost all the substrate-paint pairs belonging 408 to the upper-left cluster (small $\theta$, high strength) of Fig 8 when tested for pull-off strengths 409 show breaks of the type similar to Fig 3 (cohesive break). Most of the substrate-paints of Fig 4108 's lower-right cluster (larger $\theta$, lower strength) of Fig 8 show break similar to Fig 4 (adhesive 411 break). These coincidences suggests plausible hypothesis for a threshold contact angle but 412 further tests are needed to verify this hypothesis. 


\section{Adhesive strength of duplex paint system is competitive with the zinc-primer/bare} steel system.

The NEPCOAT qualified list of paint systems were originally tested for application of zincrich primers on bare steel substrate. In a duplex paint system the zinc-rich primer is replaced by a metallic zinc coating on the steel substrate. One question of interest was whether the

421 intermediate and top paints in a duplex paint system would have adhesive strength comparable 422 with that of the original NEPCOAT paints on bare steel.

Based on the comparison between the control panels (the $\mathrm{Z}$ panels with the organic 424 zinc-rich primers from NEPCOAT List B) and the test panels (the G0m, G0b, M0 and G2b 425 panels), the test results show that the initial pull-off strengths of the duplex system are 426 comparable with the performance of NEPCOAT system on bare steel surfaces. The 427 experimental test results also suggest that, in most cases, the intermediate epoxy paints listed 428 in qualified list B of NEPCOAT are suitable as a primer on the galvanized surface with initial 429 pull-off strengths in the 1,500 to 2,500 psi range. However, the same epoxy paints when 430 paired with the metalized zinc surface the pull-off strength is not as strong (in the 900 to 1,100 431 psi range) although higher the NEPCOAT passing score of 600 psi.

In the literature there is a perception of poor adhesion of paint on the galvanized steel.

433 The experimental results (from an admittedly small number of tests) suggest that there is no 434 reason to expect poor adhesion in all duplex paints. It was found that the pull-off strengths 435 reach the 1,500 to 2,500 psi range when the zinc surface is profiled with ordinary commercial 436 procedure. The unsightly peeling of paints from duplex painted structures is likely the result 437 of inadequate surface profiling of zinc coating of galvanized steel. 


\section{Adhesive strengths of a specific paint depends on the choice of a specific type of}

roughened zinc surfaces

All paint systems show "strong" performance in most of the profiled zinc substrates including the followings:

G0m substrate: $\quad$ Paints I and S2

G0b substrate: All paints show "strong” pull off strength. Paints I, C, S2, S1.

M0 substrate: $\quad$ Paint system S3.

G2b substrate: $\quad$ Paints C, S1 and I.

One paint system (S3) on the metalized substrate (M0) show clear advantage over the paint systems C, I, S1 and S2 (see Table 3).

\section{A Sealer (S3) for M0 substrate provides significantly better adhesion.}

Based on the data for the thermally sprayed zinc test panels (M0, metalized, painted on the same day as metalizing) the authors suggest that sealer should be always used for the Duplex Paint System on zinc-metalized surfaces.

The test results displayed in Table 3 strongly support our recommendation. The data show that the average pull-off strength for the S3 paint system (containing a sealer) is $2,023 \pm$ 480 psi. The pull-off strengths for the other NEPCOAT epoxy intermediate paints C, I, S1 and S2 are clustered in the range between 1,079 to 1,178 psi, with estimated error bars at about 200 psi.

The advantage of using a sealer for metalized steel has been recognized and has been written into state Department of Transportation (DOT) paint specifications (e.g., Rhode Island DOT metalizing specification). Thus the finding in this study is not surprising. But our data 
showed that the improvement in performance due to the use of sealant is significant. This study also showed the reason for the difference in performance.

Based on the empirical data (admittedly a small set of data) and the understanding gained from the contact angle measurement, the authors of this study recommend that sealers be always used for the zinc metalized surface. The NEPCOAT intermediate paint could be replaced by a sealer (which is how our M0-S3 panels were fabricated) or be applied on top of the sealed metalized surface.

\section{The correlation between the pull-off strengths and the contact angles.}

We found there is a negative correlation between the contact angle of a liquid paint droplet and the pull-off strength of the cured paint. As shown in Figure 7, a higher pull-off strength of a test panel is associated with a smaller contact angle measured for the corresponding intermediate paint droplet on the profiled zinc surface. This observation suggests the wetting/adhesion correlation is not limited to a single pair of paint/surface but the correlation exists for a variety of paint/surface pairs formed from 5 different epoxy paints and 3 different types of roughened zinc surfaces. The data points on a pull-off strength vs. contact angle plot are somewhat scattered but the connection between the low contact angle and strong adhesion is supported by the data. There is a correlation but not a strong correlation. The imperfect correlation is not unexpected in considering both the materials (paints, roughened surfaces) and the tests (contact angle and pulloff strength) are influenced by a number of other factors. The data show that liquid paint wetting plays important role in the adhesive strength of the paint.

The correlation between the contact angle and pull-off strength is probably not a linear function judging from the clustering of high-strength and low-angle points. More tests are needed to test this hypothesis. 
The number of tests performed in this project is not large enough for us to be confident 484 about the applicability of the contact angle/strength correlation in optimizing the paint/surface 485 pairing. Our data suggest this type of experimentally determined correlation could be a useful 486 method for selecting an optimized paint/surface match.

487

488 Acknowledgements

489 This research project was sponsored by NETC under project 05-5 administered by FHWA CT 490 Division Office. Details of the experimental data and the full report are available from NETC 491 (http://www.uvm.edu/trc/netc/). The authors thank the NETC05-5 technical committee 492 members for their guidance through out the research project: Jerry McMahan, Vermont 493 Agency of Transportation, Chairperson; Jerry Zoller, New Hampshire DOT; Denis Dubois, 494 Maine DOT; Andrew J. Mroczkowski, Connecticut DOT; Willie Feliciano, New York DOT; 495 Mary Grieco, Massachusetts Highway Department; Colin Franco, Rhode Island DOT. The 496 authors thank the following persons for their generous help: Michael Hewins, Massachusetts 497 Highway Department; Michael Sock, Rhode Island DOT; Richard Brown, Dept. of Chemical 498 Engineering, URI.

The authors thank anonymous reviewers who suggested useful clarifications including 500 the threshold model discussed in the main text.

501

502

503 


\section{References}

505

506 Bonn, D., J. Eggers, J. Indekeu, J. Meunier, E. Rolley, (2009). "Wetting and spreading”, Rev.

507 Modern Physics, 81, 739-805.

508

509 Cassie, A.B.D. and S. Baxter, (1944). "Wettability of porous surfaces," Trans. Faraday Soc.

$510 \quad 40,546$.

511

512 Chow, T.S. (1998). "Wetting of rough surfaces". Journal of Physics: Condensed Matter 10 (27):

513 L445. Bibcode:1998JPCM...10L.445C. doi:10.1088/0953-8984/10/27/001.

514

515 de Gennes, P. G. (1985). “Wetting: statics and dynamics”, Rev. Modern Physics, 57, 827.

516

517 North East Protective Coating Committee (NEPCOAT), (2016) "Qualified Products for

518 Protective Coatings for New and 100\% Bare Existing Steel for Bridges" Web page updated

519 4/2016, on-line publication url: http://www.nepcoat.org/qualprod.htm

520

521 Petries, E, "Fundamentals of paint adhesion" on-line article published May 22, 2012, web

522 page, $\quad$ http://www.materialstoday.com/metal-finishing/features/fundamentals-of-paint-

523 adhesion/

524 
525 Spori, Doris M., Tanja Drobek, Stefan Zürcher, Mirjam Ochsner, Christoph Sprecher, 526 Andreas Mühlebach, and Nicholas D. Spencer, (2008). "Beyond the Lotus Effect: Roughness 527 Influences on Wetting over a Wide Surface-Energy Range,” Langmuir, 24, pp. 5411-5417.

529 Wana, Yong, Zhongqian Wanga, Zhen Xua, Changsong Liua, and J Zhang, (2011). 530 "Fabrication and Wear Protection Performance of Superhydrophobic Surface on Zinc," 531 Applied Surface Science 257, pp. 7486-7489.

532

533 Wenzel, R. N. (1936). "Resistance of solid surfaces to wetting by water,” Ind. Eng. Chem. 28, $534988-944$.

535

536 Yang, Sze C, K. Wayne Lee, Maureen Mirville, Chen Lu, Anthony Pahram, (2013), 537 "Measurement of adhesion properties between topcoat paint and metallized/galvanized steel 538 with surface energy measurement equipment" NETCR93 Report, achieve copy available at 539 Transportation Research Center, University of Vermont. Web address: 540 http://www.uvm.edu/trc/?s=NETC

541

542 Zisman, W.A. (1964). "Relation of the Equilibrium Contact Angle to Liquid and Solid 543 Constitution", in Fowkes; "Contact Angle, Wettability, and Adhesion, American Chemical 544 Society, Advances in Chemistry, ACS Symposium Series, Vol 43, p. 1. 545 546 
Table 1. Paint Systems for Galvanized or Metalized Test Panels

\begin{tabular}{|c|c|c|c|c|c|}
\hline Paint Systems & Primer & & Intermediat & & Finish \\
\hline Paint System C & $\begin{array}{l}\text { galvanizing, } \\
\text { metalizing, } \\
\text { Carbozinc } 859\end{array}$ & $\begin{array}{l}\text { or } \\
\text { or }\end{array}$ & $\begin{array}{l}\text { Carboline } \\
\text { Epoxy }\end{array}$ & 888 & $\begin{array}{l}\text { Carboline } 133 \text { LH } \\
\text { Aliphatic } \\
\text { Polyurethane }\end{array}$ \\
\hline Paint System I & $\begin{array}{l}\text { galvanizing } \\
\text { metalizing, } \\
\text { Interzinc } ₫ 52\end{array}$ & $\begin{array}{l}\text { or } \\
\text { or }\end{array}$ & $\begin{array}{l}\text { Intergard } \\
\text { Epoxy }\end{array}$ & 345 & Interthane $870 \mathrm{UHS}$ \\
\hline Paint System S1 & $\begin{array}{l}\text { galvanizing } \\
\text { metalizing, } \\
\text { Zinc Clad III }\end{array}$ & $\begin{array}{l}\text { or } \\
\text { or }\end{array}$ & $\begin{array}{l}\text { Macropoxy } \\
\text { Fast Cure E }\end{array}$ & 646 & $\begin{array}{l}\text { Acrolon } 218 \text { HS } \\
\text { Acrylic Polyurethane }\end{array}$ \\
\hline Paint System S2 & $\begin{array}{l}\text { galvanizing } \\
\text { metalizing, } \\
\text { Zinc Clad III }\end{array}$ & $\begin{array}{l}\text { or } \\
\text { or }\end{array}$ & $\begin{array}{l}\text { Recoatable } \\
\text { Primer Seri }\end{array}$ & $\begin{array}{l}\text { Epoxy } \\
367\end{array}$ & $\begin{array}{l}\text { High Solids } \\
\text { Polyurethane Series } \\
\text { B58 }\end{array}$ \\
\hline Paint System S3 & Metalizing & & $\begin{array}{l}\text { Macropoxy } \\
\text { Sealer }\end{array}$ & 920 & $\begin{array}{ll}\text { Acrolon } 218 & \text { HS } \\
\text { Acrylic } & \\
\text { Polyurethane } & \end{array}$ \\
\hline
\end{tabular}

Note: The paint system S3 was applied to substrate M0 only. It was not used for other metal substrates. 
552 Table 2. Paint Systems for Control Panels

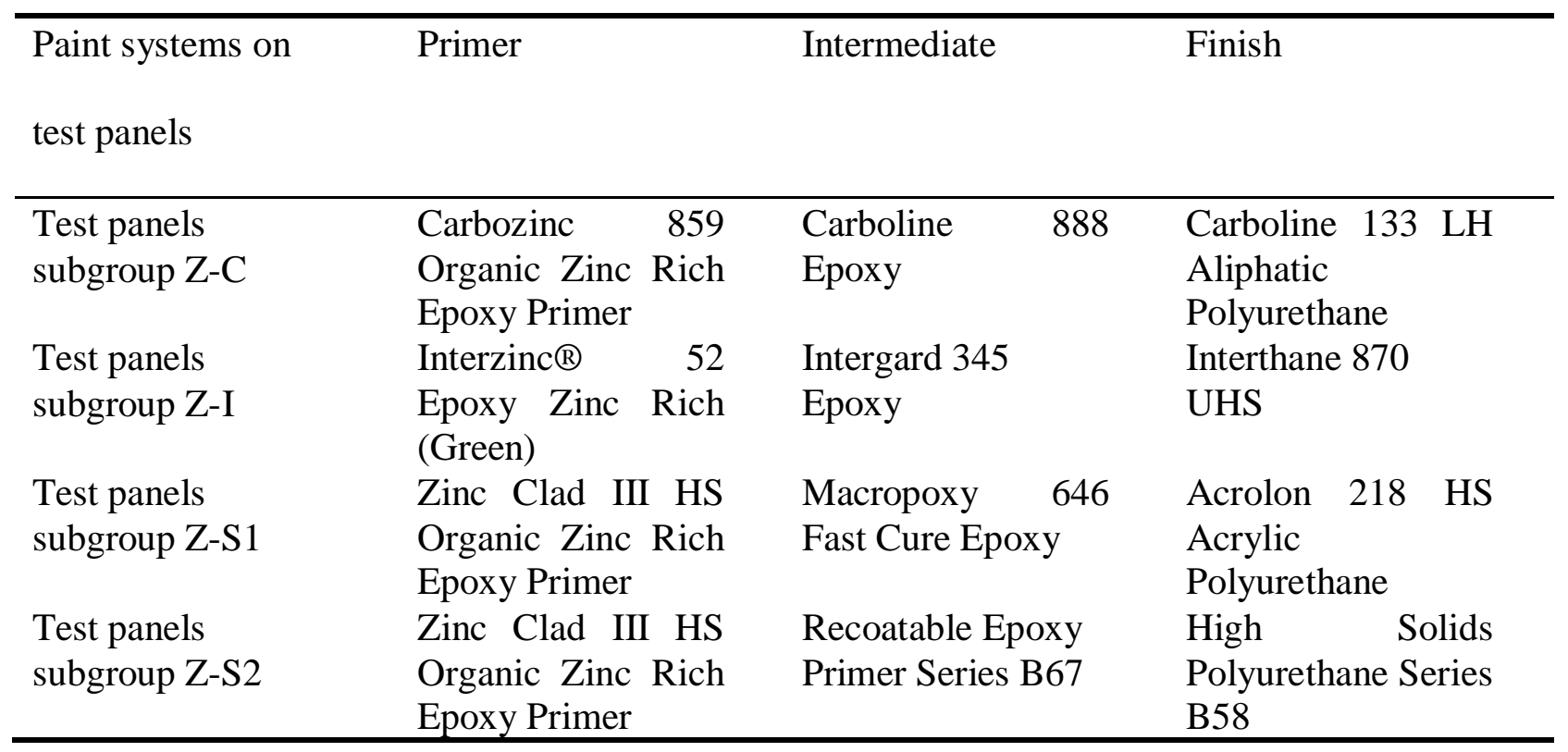


554 Table 3. Correlation between the Average Pull-off Strengths and the Average Contact Angles

\begin{tabular}{|c|c|c|c|}
\hline Subgroup label & $\begin{array}{l}\text { Average Pull-off } \\
\text { Strength (psi) }\end{array}$ & $\begin{array}{c}\text { Average Contact Angle } \\
\text { (degree) }\end{array}$ & $\begin{array}{l}\text { Average score } \\
\text { ASTMD-3359 } \\
\text { (Ranking 1-5) }\end{array}$ \\
\hline G0m-I & 2525 & 36 & 5.00 \\
\hline $\mathrm{G} 2 \mathrm{~b}-\mathrm{C}$ & 2502 & 36 & 5.00 \\
\hline G2b-S1 & 2389 & 46 & 5.00 \\
\hline G2b-I & 2257 & 35 & 5.00 \\
\hline G0b-I & 2052 & 37 & 5.00 \\
\hline G0b-C & 2038 & 37 & 5.00 \\
\hline M0-S3 & 2023 & 0 & 5.00 \\
\hline G0m-S2 & 1988 & 42 & 5.00 \\
\hline G0b-S1 & 1815 & 46 & 4.75 \\
\hline G2b-S2 & 1742 & 35 & 5.00 \\
\hline G0m-S1 & 1650 & 106 & 5.00 \\
\hline G0m-C & 1372 & 82 & 4.75 \\
\hline M0-C & 1178 & 87 & 4.88 \\
\hline M0-S2 & 1103 & 58 & 4.75 \\
\hline M0-I & 1087 & 75 & 4.88 \\
\hline G0b-S2 & 1083 & 54 & 4.75 \\
\hline M0-S1 & 1079 & 103 & 4.88 \\
\hline
\end{tabular}

